\title{
Aplicação de Imageamento Elétrico Multi-eletrodos para Auxílio na Locação de Perfuração de Poços Tubulares - Estudo de Casos em Aquíferos Cristalinos
}

Henrique de Sá (IAG/USP), Vagner Roberto Elis (IAG/USP)

Copyright 2016, SBGf - Sociedade Brasileira de Geofísica

Este texto foi preparado para a apresentação no VII Simpósio Brasileiro de Geofísica. Ouro Preto, 25 a 27 de outubro de 2016. Seu conteúdo foi revisado pelo Comitê Técnico do VII SimBGf, mas não necessariamente representa a opinião da SBGf ou de seus associados. É proibida a reprodução total ou parcial deste material para propósitos comerciais sem prévia autorização da SBGf.

\section{Resumo}

Com o aumento da crise hídrica aumentou a perfuração de poços tubulares e consequentemente a procura de métodos para se identificar aquíferos. Para esta finalidade, a geofísica aplicada tem sido cada vez mais procurada. Neste trabalho, utilizando a técnica geoelétrica de imageamento elétrico multieletrodos a geometria variável visou-se localizar lineamentos estruturais nas rochas em subsuperfície, aptas a armazenar água. Analisou-se dois casos de aquíferos em rochas cristalinas: i) metassedimentos e corpos graníticos do Grupo Araxá; ii) e nos domos gnáissicos-migmatíticos da Formação Itabaiana Simão Dias. Os dados adquiridos foram processados e interpretados de acordo com informações geológicas de cada região. Para avaliar a resposta geofísica em ambas as situações os poços foram perfurados de acordo com 0 resultado do imageamento elétrico.

\section{Introdução}

A aplicação de pesquisa geofísica para locação de poços tubulares tem sido intensificada por causa do aumento do número de perfurações tanto pela indústria como por condomínios. O motivo é a crescente crise hídrica, especialmente no sudeste do país, como por exemplo se intensificou no estado de São Paulo a partir de janeiro de 2014. Diante disso é de essencial importância analisar a eficácia do método geoelétrico, que visa investigar a subsuperfície da região estudada através de valores de resistividade elétrica.

Neste trabalho será tratado de um avanço tecnológico da técnica de caminhamento elétrico, denominada de Imageamento Elétrico Multi-eletrodos (IEM), que basicamente trata-se da aquisição detalhada de valores de resistividade elétrica aparente do subsolo permitindo gerar uma "imagem" 2D da variação de resistividade em subsuperfície. A técnica é multi-eletrodos, por utilizar diversos polos simultaneamente permitindo além da maior quantidade de dados, uma maior velocidade de aquisição.

O presente trabalho visa analisar de forma prática a eficácia deste tipo de ferramenta, ou seja, considerando dois casos reais de pesquisas geofísicas realizadas buscando auxiliar na definição de locais e profundidades da perfuração de novos poços tubulares. Os casos estão associados com aquíferos cristalinos, onde os locais aconselháveis para perfuração de poços são geralmente os relacionados com pontos de fraqueza do substrato rochoso (falhas, fraturas, entre outros). Portanto analisarse-á se o método geoelétrico, nestes dois contextos geológicos, obtém êxito em encontrar esses lineamentos estruturais.

O primeiro caso é em uma indústria de laticínios denominada Italac, localizada em Corumbaíba, Goiás, presente no Grupo Araxá, composta por rochas xistosas. O segundo caso localiza-se em Moita Bonita, Sergipe, região de transição para o sertão neste estado, no domo da Formação Itabaiana-Simão Dias, compondo um embasamento gnáissico.

O resultado do IEM tentará identificar terrenos soltos, rocha alterada e rocha sã, reconstruindo a eletroestratigrafia, além de localizar anomalias e contatos laterais na sequência das camadas em profundidade. 0 objetivo é reconstruir, através de um modelo baseado na resistividade aparente do meio, baseado nas possibilidades estruturais indicadas pelas informações geológicas regionais, a real situação em subsuperfície, de forma a localizar, caso haja, aquíferos.

\section{Imageamento Elétrico Multi-eletrodos 2D -} Configuração Polo-dipolo à Geometria Variável

Os métodos de prospecção geoelétrica permitem a reconstrução estratigráfica do subsolo utilizando como parâmetro físico a resistividade elétrica aparente das formações que o constituem.

A resistividade $(\rho)$ é um parâmetro independente das características geométricas das formações litológicas, e é definida como a relação entre a diferença de potencial (ao dipolo de medida, $\Delta \mathrm{V}$ ) e corrente (introduzida no terreno, I), relação que é multiplicada por um oportuno fator geométrico dependente da posição recíproca dos eletrodos $(\mathrm{K})$.

$$
\rho=\frac{K \Delta V}{I}
$$

Se supormos executar as medidas sobre um semiespaço de resistividade homogênea, o fator geométrico $\mathrm{K}$ seria o valor que serviria para tornar o termo direito da Eq. 1 igual ao valor de resistividade do semi-espaço. Variando $\Delta \mathrm{V} / \mathrm{I}$ para os diversos dipolos, $\mathrm{K}$ é um valor que 
depende somente da posição dos eletrodos de corrente $(A$ e $B)$ e de potencial $(M$ e $N)$.

$$
\boldsymbol{K}=\frac{2 \pi}{\left(\frac{1}{A M}\right)-\left(\frac{1}{A N}\right)-\left(\frac{1}{B M}\right)+\left(\frac{1}{B N}\right)}
$$

As linhas de Imageamento Elétrico Multi-eletrodos 2D foram realizadas com até 48 eletrodos equidistantes (Fig. 1). A configuração usada é conhecida como "polo-dipolo à geometria variável".

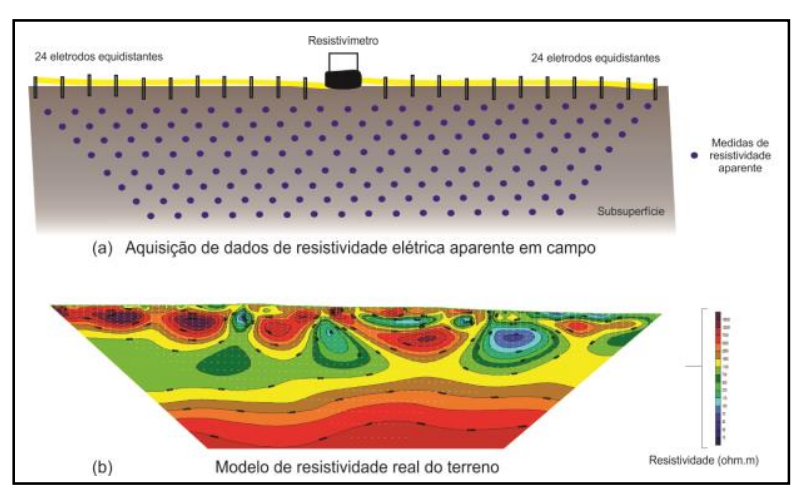

Figura 1 - Ilustração da (a) configuração em campo do imageamento elétrico multi-eletrodos e correspondente (b) modelo de resistividade real do terreno.

As medidas de potencial são realizadas em sequência em várias duplas de eletrodos "M-N" colocados em linha, oportunamente selecionados, de forma automática, pelo resistivímetro ABM Al48-c.

A distância entre os eletrodos de potencial depende do detalhe que seja necessário alcançar e da profundidade a ser estudada: em Corumbaíba (GO) foi utilizado um espaçamento de $5 \mathrm{~m}$ entre cada eletrodo, para pesquisar uma profundidade máxima de aproximadamente $80 \mathrm{~m}$ com um detalhe decrescente com a profundidade. $O$ passo 10 e $6 \mathrm{~m}$ foi utilizado, respectivamente, para 0 primeiro e segundo perfil realizado em Moita Bonita (SE), sendo que as correspondentes profundidades alcançadas foram em torno de 160 e $96 \mathrm{~m}$.

O nome "polo-dipolo à geometria variável" deve-se a que, nesta configuração, o campo elétrico é gerado por um: i) primeiro polo de corrente chamado "A", colocado no interior da linha de medida, o qual é selecionado e deslocado de forma automática pelo resistivímetro para o interior da mesma linha em correspondência aos 48 eletrodos e; ii) segundo polo de corrente chamado "B" (que atua conjuntamente com o "A") colocado "ao infinito" (ou seja, a uma distância relativamente grande da linha de medição).
As seções geoelétricas 2D, constituem o modelo de resistividade real do terreno, e fornecem um corte vertical deste (Fig. 1b) com uma grande quantidade de dados de resistividade (Fig. 1a), com mediamente 14 níveis de profundidade, possíveis graças à geometria variável, que funciona aumentando o espaçamento dos dipolos de medida com a distância do polo de corrente, acompanhado por um aumento progressivo e linear do potencial lido.

\section{Aquisição e Tratamento dos Dados}

A obtenção dos dados foi realizada pelo resistivímetro ABM AL48-C, com um energizador interno de $300 \mathrm{~W}$ e capaz de prover uma tensão elétrica de até $700 \mathrm{~V}$ aos cabos de medida, em grau de adquirir até 48 canais simultaneamente (Fig. 1a) e de comandar automaticamente a inversão da corrente. Nesta configuração, o resistivímetro comanda, de forma síncrona, o gerador interno, com geração de ondas quadras.

Os dados de resistividade aparente foram medidos e processados através do software RES2DINV. A inversão dos dados de resistividade foi conduzida pelo método dos mínimos quadrados envolvendo métodos de diferenças finitas e elementos finitos.

Tratando-se de uma morfologia irregular, foi aplicada a correção topográfica com base nos dados topográficos levantados sucessivamente à campanha geofísica.

\section{Localização e Contexto Geológico das Regiões de Estudo}

Duas linhas de pesquisa geoelétrica foram analisadas em Corumbaíba, Goiás, na área da indústria de laticínios Italac na Rodovia GO-139, s/n, Setor Industrial, conforme o mapa na Fig. 2. As coordenadas do primeiro e último eletrodo $\left(n^{\circ} 48\right)$ da linha 1 são, de acordo com o Datum WGS 84: $18^{\circ} 6^{\prime} 14.36^{\prime \prime} \mathrm{S}, 48^{\circ} 33^{\prime} 42.92^{\prime \prime}$ O e $18^{\circ} 6^{\prime} 17.90^{\prime \prime} \mathrm{S}$, $48^{\circ} 33^{\prime} 50.35^{\prime \prime} \mathrm{O}$, respectivamente. Considerando 0 mesmo Datum, o eletrodo 1 da linha 2 está em $18^{\circ} 6^{\prime} 8.88^{\prime \prime}$ $\mathrm{S}, 48^{\circ} 33^{\prime} 44.35^{\prime \prime} \mathrm{O}$ enquanto o eletrodo 48 se encontra em $18^{\circ} 6^{\prime} 4.32 "$ S, 48 $33^{\circ} 51.42^{\prime \prime}$ O. Ambas as linhas têm $235 \mathrm{~m}$ de comprimento.

A área de estudo se encontra no Grupo Araxá, constituído por uma sequência de metassedimentos e corpos graníticos associados. Segundo Queiroz et. al. (2000) os principais lineamentos estruturais nesta região são na direção noroeste-sudeste, por este motivo a linha geoelétrica 1 foi traçada na direção sudoeste-nordeste, visando, com um ângulo próximo ao de $90^{\circ}$, identificar esses lineamentos principais ou secundários. A linha 2 foi traçada perpendicular à primeira, para tentar compreender a região em mais de uma direção. Outro motivo para o traçado da linha 2 foi a presença de um rio paralelo a esta; geralmente existem fraturas ou mesmo falhamentos cruzando os rios, portanto uma linha de pesquisa geoelétrica paralela ao rio pode identificar estas anomalias estruturais. 


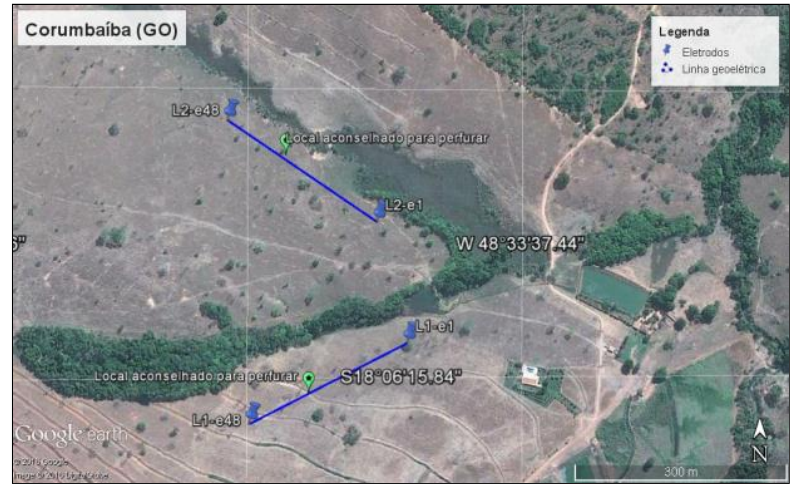

Figura 2 - Disposição das linhas geoelétricas 1 e 2 na indústria de laticínios em Corumbaíba (GO) com as indicações dos locais para perfuração dos poços.

Em Moita Bonita (SE) também duas linhas foram obtidas, porém apenas o perfil ao longo do qual o poço foi perfurado será demonstrado neste trabalho. As coordenadas do primeiro eletrodo da primeira linha são, de acordo com o Datum WGS 84: 10³4'31.63" S, 37²0'26.29" O; e do último eletrodo: $10^{\circ} 34^{\prime} 25.27^{\prime \prime} \mathrm{S}$, $37^{\circ} 20^{\prime} 39.95^{\prime \prime} \mathrm{O}$. E as coordenadas do primeiro eletrodo da segunda linha são: $10^{\circ} 34^{\prime} 34.34^{\prime \prime}$ S, 37²0'28.64" O; e do último eletrodo: $10^{\circ} 34^{\prime} 25.64^{\prime \prime} \mathrm{S}, 37^{\circ} 20^{\prime 26.68 " ~ O . ~ A ~}$ primeira linha tem $470 \mathrm{~m}$ de comprimento (47 espaçamentos de $10 \mathrm{~m}$ com 48 eletrodos) enquanto a segunda tem $282 \mathrm{~m}$ (passo $6 \mathrm{~m}$ ). Esta é menor devido a limitação de espaço para estender os cabos multipolares.

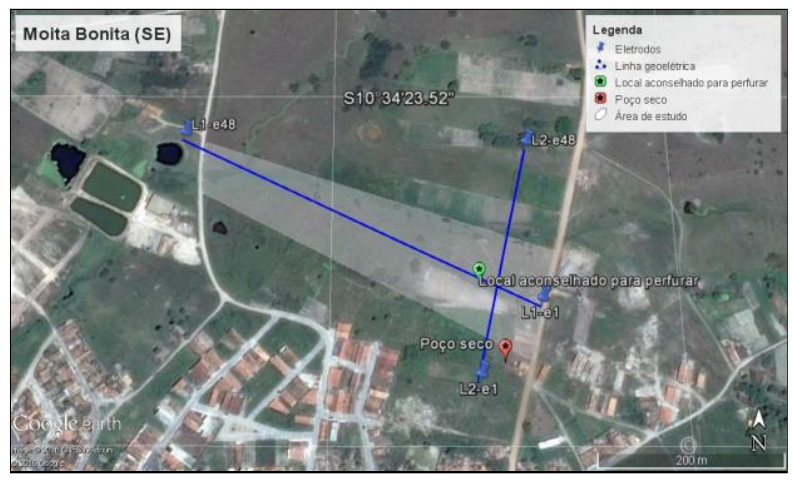

Figura 3 - Disposição das linhas geoelétricas 1 e 2 na propriedade em Moita Bonita (SE) com a indicação do local para perfuração do poço.

No local pesquisado há afloramento do embasamento cristalino arqueano / paleoproterozóico da Formação Itabaiana - Simão Dias, composta por domos gnáissicosmigmatíticos (Uhlein et al., 2011). O traçado da linha 1 foi definido de forma longitudinal ao polígono de estudo, conforme a Fig. 3, sendo a linha 2 perpendicular a esta, para também poder compreender a geologia em subsuperfície em mais de uma direção. Segundo o banco de dados corporativo (Geobank) da CPRM (Serviço
Geológico do Brasil) as principais tendências dos lineamentos estruturais nesta região são oés-noroeste és-sudeste (ONO-ESE); porém, lineamentos de menor expressão, mas mais próximos, estão na direção sudoeste-nordeste (SO-NE). Desta forma a linha 1 foi disposta apta a identificar estes lineamentos mais próximos, enquanto a linha 2 poderia identificar os lineamentos regionais.

Tanto em Corumbaíba quanto em Moita Bonita o que se espera é que o perfil geoelétrico cruze possíveis falhas ou fraturas conforme o modelo na Fig. 4, aumentando as chances de perfuração de poços produtivos.

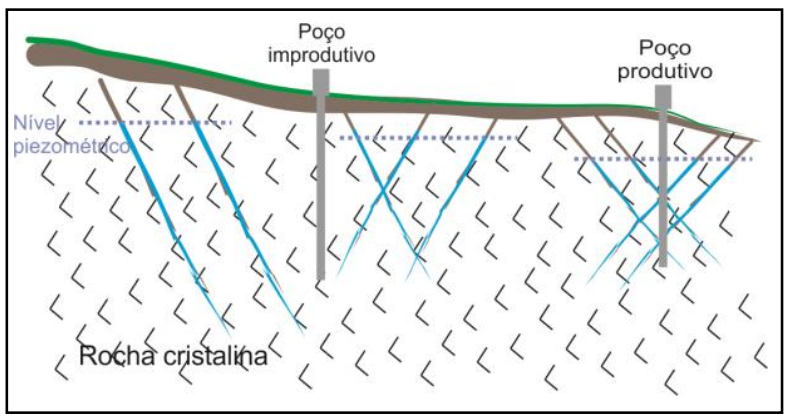

Figura 4 - Modelo de aquífero cristalino.

\section{Resultados}

A Fig. 5a mostra o modelo de resistividade real do terreno ao longo da linha de pesquisa geoelétrica 1. Entre 140 e 235 m de comprimento há uma região de cerca de $5 \mathrm{~m}$ de espessura com baixa resistividade (100 a 300 ohm.m) contrastando com uma zona de alta resistividade (até 4.000 ohm.m) que se estende até o limite lateral a sudoeste e em profundidade estudado por este perfil. Zona resistiva semelhante a esta aparece novamente no polígono que se estende ao longo do comprimento de 40 e $55 \mathrm{~m}$ da linha de pesquisa, delimitado na parte superior pela profundidade de cerca de $5 \mathrm{~m}$ e se estendendo até o limite inferior estudado pelo perfil. A parte central do perfil, de 60 a $140 \mathrm{~m}$ de comprimento há de 0 a cerca de $20 \mathrm{~m}$ de profundidade a presença de terrenos fortemente condutivos, a partir desta profundidade há uma tendência gradual de aumento de resistividade. Considerando as informações geológicas da região, com afloramentos rochosos, pressupõe-se que as zonas resistivas correspondem à rocha sã; a camada superficial de cerca de $5 \mathrm{~m}$ de espessura pode ser uma camada de solo e rocha alterada; enquanto a zona relativamente condutiva na região central do perfil deve corresponder a lençol freático ou terrenos soltos argilosos acumulados devido ao rebaixamento dessa região central por causa de um falhamento, este indicado no modelo geológico na Fig. $5 b$.

O perfil 2, contido na Fig. 6a, demonstra certa correspondência com o perfil 1: zona resistiva no polígono entre 170 e 235 m de comprimento, a partir de 5 $\mathrm{m}$ de profundidade até o final inferior e noroeste do perfil; região central com gradual aumento da resistividade dos 
terrenos a partir de $5 \mathrm{~m}$ de profundidade até o limite inferior investigado. Interpretação, baseada nas informações geológicas e no perfil 1, é dada por uma camada superficial de aproximadamente $5 \mathrm{~m}$ de espessura, composta pela camada superior anômala, de 0 a 170 m de comprimento (mais resistiva que a camada inferior); zona resistiva, sendo identificada como rocha sã, tanto a forte zona resistiva a noroeste quanto a tendência ao aumento da resistividade a medida que aumenta a profundidade ao longo de todo o perfil. Mais uma vez a zona central fortemente condutiva em relação a zona resistiva pode ser identificada como lençol freático ou mesmo a presença de terrenos soltos argilosos ocupando o espaço gerado pelo falhamento indicado pela linha tracejada.

Considerando que há a presença de fortes lineamentos estruturais na região que se supõe que cruzam os perfis geoelétricos, optou-se pela interpretação da presença de falhamentos nos dois perfis. Diante disso os poços foram locados visando atingir os falhamentos em profundidade, conforme indica os triângulos em 157 m (Fig. 5b) e 153 m (Fig. 6b) de comprimento do perfil 1 e 2 , respectivamente.

Perfurados os poços, em ambos: a presença da rocha sã foi confirmada e a vazão obtida foi entre 12 e $15 \mathrm{~m}^{3} / \mathrm{hora}$, considerada alta em relação aos poços anteriormente existentes. Informações mais específicas a respeito da perfuração, como perfil litológico, não puderam ser divulgadas.

Em Moita Bonita, Sergipe, foi adquirido o perfil contido na Fig. 7a. Verifica-se uma camada superficial em torno de $10 \mathrm{~m}$ de espessura com resistividades relativamente baixas (<100 ohm.m) se mantendo regularmente sobre uma camada resistiva (até $4.000 \mathrm{ohm}$.m) que se estende abaixo desta até o limite inferior da pesquisa geoelétrica; essa regularidade tem exceção em quatro locais: no comprimento do perfil em torno de 160 , 300 e $430 \mathrm{~m}$ onde essa faixa superficial mais condutiva se expande além da generalização de $10 \mathrm{~m}$ de profundidade até aproximadamente $20-25 \mathrm{~m}$; e entre 75 e $105 \mathrm{~m}$ de comprimento do perfil há uma forte anomalia horizontal, onde a zona resistiva é interrompida verticalmente pela zona condutiva.

Na região de estudo já havia sido perfurado um poço a cerca de $70 \mathrm{~m}$ a sul deste perfil (poço seco, em vermelho, na Fig. 3), onde o topo da rocha sã iniciou em torno de 8 $\mathrm{m}$ de profundidade. Portanto pôde-se supor que a zona condutiva se trata de terrenos soltos enquanto a zona resistiva representa a rocha sã. A Fig. $7 \mathrm{~b}$ relaciona 0 perfil geofísico da Fig. 7a com modelos de aquíferos cristalinos que contêm falhamentos/fraturamentos subverticais. Nestes é normal a presença de terrenos argilosos e/ou água gerando baixa nas medidas de resistividade.

Por isso, locou-se o poço tubular ao longo de $75 \mathrm{~m}$ de comprimento deste perfil mais uma vez visando encontrar a falha/fratura em profundidade. Sugeriu-se a perfuração até $50 \mathrm{~m}$ de profundidade, porém observa-se no perfil que essa zona condutiva, com possível presença de água, já se encontra a partir de cerca de $20 \mathrm{~m}$ de profundidade. Feita a perfuração, relatou-se que em $18 \mathrm{~m}$ iniciou a vazão de água do poço. Este foi perfurado até $45 \mathrm{~m}$ de profundidade, contendo vazão de $2.5 \mathrm{~m}^{3} / \mathrm{h}$ (conforme teste de vazão). A rocha sã conforme 0 primeiro poço e a indicação do perfil geoelétrico iniciou em $8 \mathrm{~m}$ de profundidade.

\section{Discussão e Conclusões}

Nas duas regiões de estudo o perfil geoelétrico definiu bem a anomalia horizontal identificada como falhas ou fraturas, sendo que em Moita Bonita - SE consegue inclusive definir aproximadamente a espessura daquela. A alta densidade de dados permite uma resolução de $1 \mathrm{~m}$ para os dois perfis em Corumbaíba (GO), realizados a passo $5 \mathrm{~m}$ entre cada eletrodo, e $2 \mathrm{~m}$ para o perfil em Moita Bonita (SE), onde foi utilizado o passo $10 \mathrm{~m}$. O método geoelétrico se mostra viável para identificar aquíferos cristalinos pelo fato destes gerarem alto contraste da propriedade de resistividade elétrica, principalmente por causa da presença de terrenos úmidos e/ou argila nesses lineamentos estruturais, que geralmente diminuem consideravelmente a resistividade aparente da região, contrastando com a maior resistividade geralmente de rochas sãs. Além disso, a geoelétrica foi eficiente para definir o topo rochoso, conforme verificado pelo poço perfurado em Moita Bonita, onde a rocha sã iniciou em torno de $8 \mathrm{~m}$, correspondendo ao imageamento elétrico.

É importante ressaltar que os dados geofísicos sem associações geológicas abrem espaço para inúmeras possibilidades sendo arriscado tomar decisões baseando-se apenas nesse critério de informações, por isso foi utilizado o termo "auxílio" no título do presente trabalho. Tratando-se de utilizar o método geoelétrico para auxiliar na locação de poços tubulares deve-se, no mínimo: 1) compreender que tipo de aquífero pode existir na região, aquífero cristalino, sedimentar ou cárstico; 2) verificar a existência de poços já perfurados próximos à região de estudo, visando conhecer a profundidade da rocha sã, litologias presentes, regiões favoráveis (poços com boa vazão de água) e regiões não favoráveis (alta taxa de poços secos) à perfuração; 3) ter uma noção da profundidade necessária a ser estudada, lembrando que esta não depende apenas do espaçamento entre eletrodos utilizados, mas também da geologia local, sendo que se houver terrenos altamente condutivos em superfície e altamente resistivos em profundidade a profundidade de investigação será prejudicada, enquanto caso ocorra o posto esta será beneficiada.

Realizar um estudo geofísico prévio à perfuração demonstrou-se muito útil. Quando se analisa, por exemplo, o caso em Moita Bonita, ao longo dos 470 metros de linha geoelétrica estudada verificou-se a presença de local viável para perfurar apenas na região entre 60 e $100 \mathrm{~m}$ de comprimento do perfil, ou seja, uma linha de $40 \mathrm{~m}$, o que corresponde a cerca de apenas $8,5 \%$ de chance de acerto caso a escolha do local fosse feita aleatoriamente sem estudo prévio. No caso em Corumbaíba os diretores da empresa de laticínios Italac 
relataram que os poços indicados através da geofísica são os que obtiveram maiores vazões quando comparados a poços perfurados sem o uso da geofísica.

\section{Agradecimentos}

Os autores agradecem ao diretor de operações, Carlos, da Italac de Corumbaíba (GO) e ao proprietário da fazenda em Moita Bonita (SE), Henrique Andrade, pelas informações fornecidas com relação aos poços perfurados e pela confiança em permitir que realizássemos as referidas pesquisas geofísicas. Henrique de Sá agradece ao CAPES pela bolsa de mestrado.

\section{Referências}

Braga, A. C. de O., 2016. Geofísica Aplicada: Métodos Geoelétricos em Hidrogeologia. Oficina de Textos, São Paulo.

Muslim B. Aminu, Tunde M. Akande, and Olubukola A. Ishola, 2014. 2D Geoelectric Imaging of the UnemeNekhua Fracture Zone. International Journal of Geophysics, vol. 2014, Article ID 842812, 8 pages.
Navarro, G. R. B., Zanardo, A., Conceição, F. T., 2013. O Grupo Araxá na Região Sul-Sudoeste do Estado de Goiás. Geol. USP, Sér. cient., São Paulo, v. 13, n. 2, p. 528.

Nigm, A. A., 2013. Geoelectric Study for Water Well Location in the Campus of Taif University, Taif, Saudi Arabia. International Journal of Water Resources and Arid Environments 2(4): 195-204.

Queiroz, C. L., Meneses, P. R., Jost, H., 2000. Lineamentos em Imagens de Sensores Remotos e seu Significado Estrutural nos Terrenos Granito-Greenstone Belt De Orixás (GO). Revista Brasileira de Geociências 30(4):655-662.

Uhlein, A., Caxito, F. A., Sanglard, J. C. D., Uhlein, G. J., Suckau, G. L., 2011. Estratigrafia e tectônica das faixas neoproterozóicas da porção norte do Craton do São Francisco. Geonomos, vol. 19, n. 2, Edição Especial - 30 Anos do CPMTC.

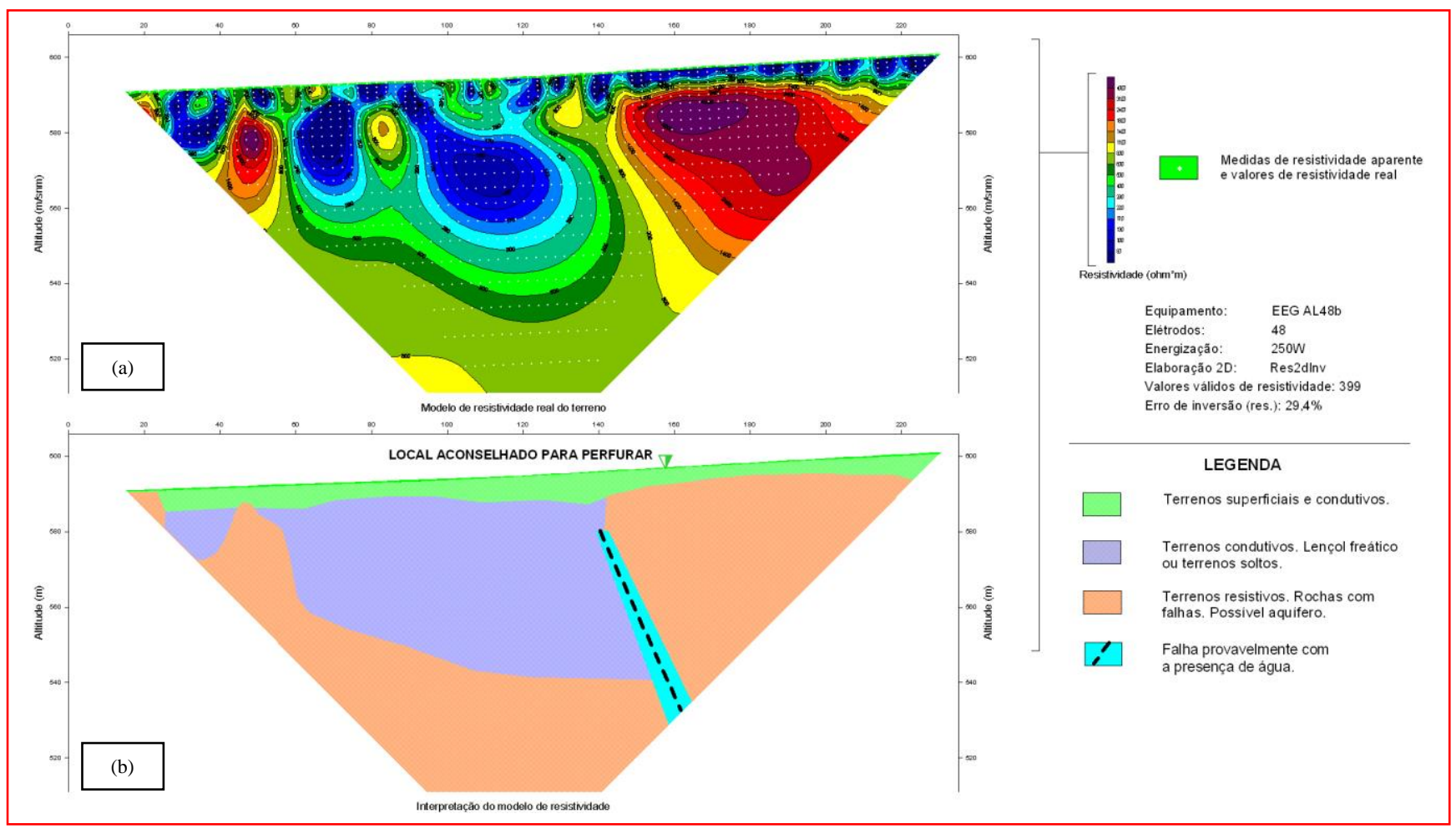

Figura 5 - (a) Modelo de resistividade real do terreno da linha 1 de pesquisa em Corumbaíba (GO) e seu correspondente (b) perfil interpretado. 


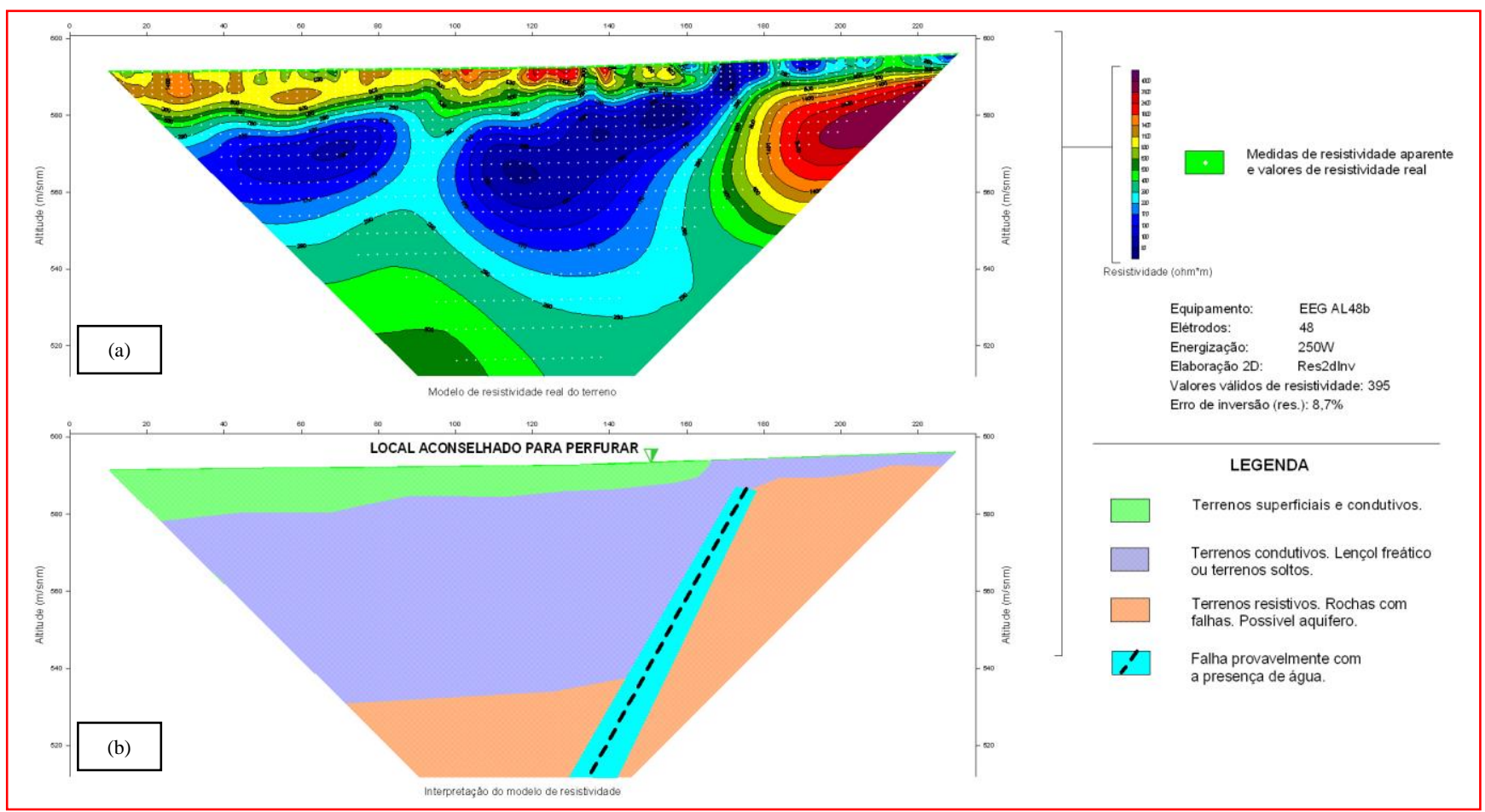

Figura 6 - (a) Modelo de resistividade real do terreno da linha 2 de pesquisa em Corumbaíba (GO) e seu correspondente (b) perfil interpretado.

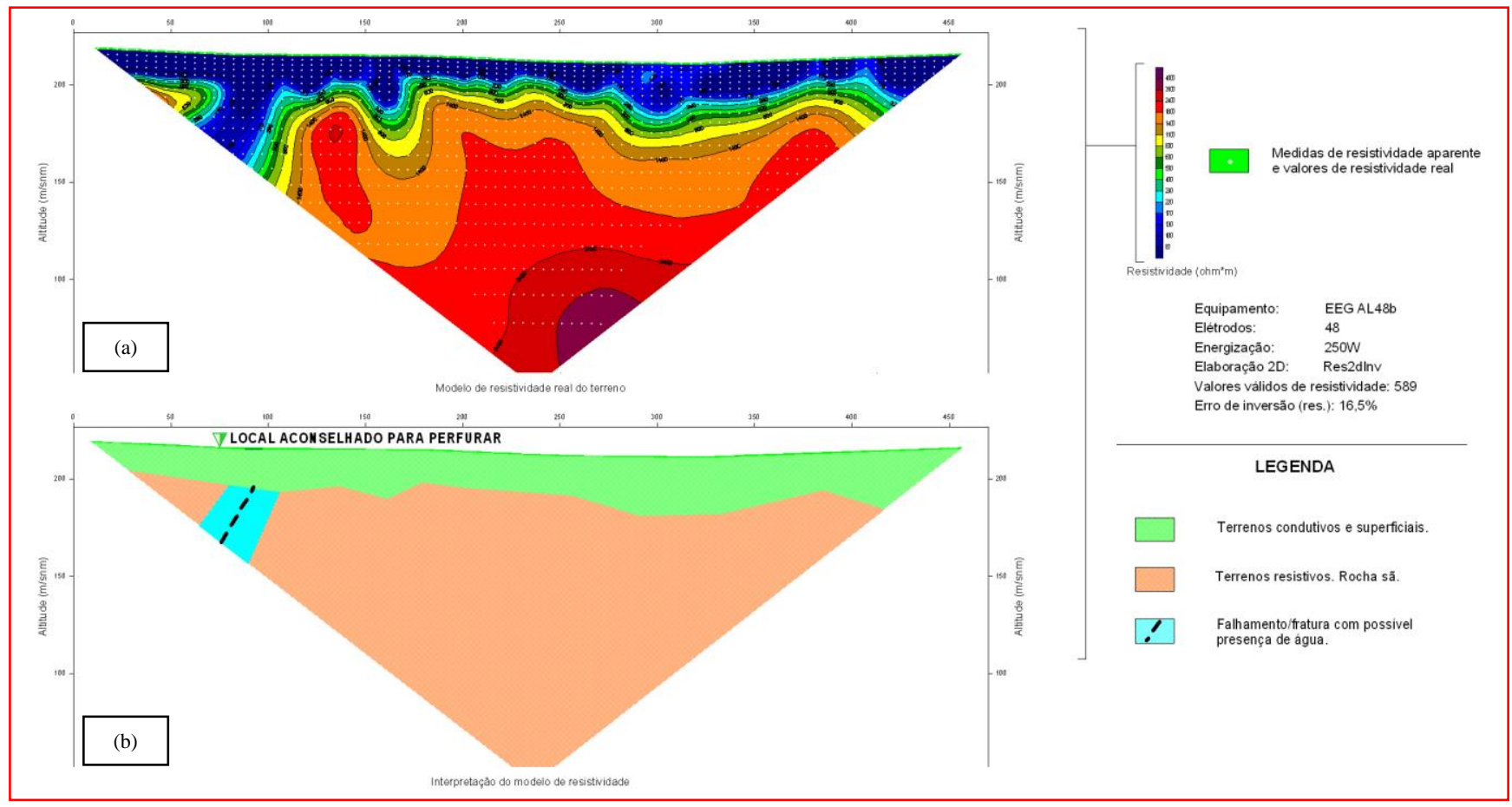

Figura 7 - (a) Modelo de resistividade real do terreno da linha 1 de pesquisa em Moita Bonita (SE) e seu correspondente (b) perfil interpretado. 